\title{
UbuWeb (em três movimentos)
}

\section{Ana Bigotte Vieira}

Projecto CASA,

Pizz Buin 2007

The Coca Cola Project partir do original de Cildo

Meireles, 1970

fot. João Martins.

Projecto CASA

Pizz Buin 2007:

Port-boteilles,

a partir do orginal de Marcel Duchamp, 1914,

fot. João Martins.

Cf. Lazuly 2003: o moto

de busca google deve popularidade à clareza do

seu estilo tipográfico (em

fundo branco e quase sem anúncios) pelo Tschichold,

no manifesto da Novo

Tipografia, havia ja preconizado que "

essência da Nova

Tipografia é a clareza

Ana Bigotte Vieira

é nvestigadora de

Estudos Artísticos

(artes do corpo nos

anos $80 / 90$ )

e bolseira da FCT.
Primeiro movimento: As técnicas das vanguardas como ferramentas de software (Manovich 2000)

Ter várias janelas abertas em simultâneo, transformar o positivo da imagem no seu negativo, escolher os caracteres de acordo com uma clara hierarquia visual que involuntariamente nos prende a atenção, fazer zoom, cut ou copy-paste, importar objectos ready-made para outro ambiente, misturar formatos de modo a criar objectos híbridos, mudar de ponto de vista, saturar as cores, fazer misturas (aleatórias ou não), ampliar, arrastar, distorcer multiplicar, sobrepor, "pixelizar", tornar sexy, esbater diferenças ou acentuar contrastes são procedimentos naturais quando trabalhamos no computador - fazem parte, como ferramentas, do próprio modo de o utilizar e, como tal, estruturam e orientam o próprio modo de acesso à informação que, sendo o resultado de investigações e escolhas várias, é muito menos neutro ou natural do que à primeira vista nos parece ${ }^{1}$.

Lev Manovich, que tem amplamente investigado os computadores enquanto medium e os utensilios de que as suas interfaces dispõem para que neles (e com eles) se trabalhe, chama a atenção para o facto de estas ferramentas informáticas não serem senão uma incorporação das novas técnicas para olhar e representar o mundo (animadas pela vontade de o transformar) desenvolvidas pelas vanguardas dos anos 20. Assim, abrir várias janelas em simultâneo resultaria da "síntese de duas técnicas básicas do cinema do séc. XX: a montagem linear e sequencial e a montagem no interior do plano" (2000: 427); fazer uma composição gráfica no computador ou o modo como as próprias ferramentas para o fazer foram desenhadas utilizaria as técnicas (hierarquia dos caracteres, dinamismo da composição, colagem...) da "Nova tipografia"; observar a partir de estranhas perspectivas reactualizaria o gesto de ostranenie avançado pelo crítico russo Schklovsky em relação à literatura e rapidamente incorporado pela "Nova visão" de Moholy-Nagy na Alemanha ou por Rodchenko na Rússia, e assim por diante.

De acordo com Manovich o que caracterizaria os novos media - que o autor entende como uma nova vanguarda - seria não a criação de "novas maneiras de olhar e representar o mundo, mas sim [de] novas formas de acesso e utilização dos meios acumulados anteriormente. A este respeito os novos media [seriam] pós-media ou meta-media, uma vez que usam os velhos media como material de base" (Ibidem: 434) e utilizam as (entretanto codificadas e "naturalizadas") técnicas desenvolvidas pelas vanguardas como ferramentas.
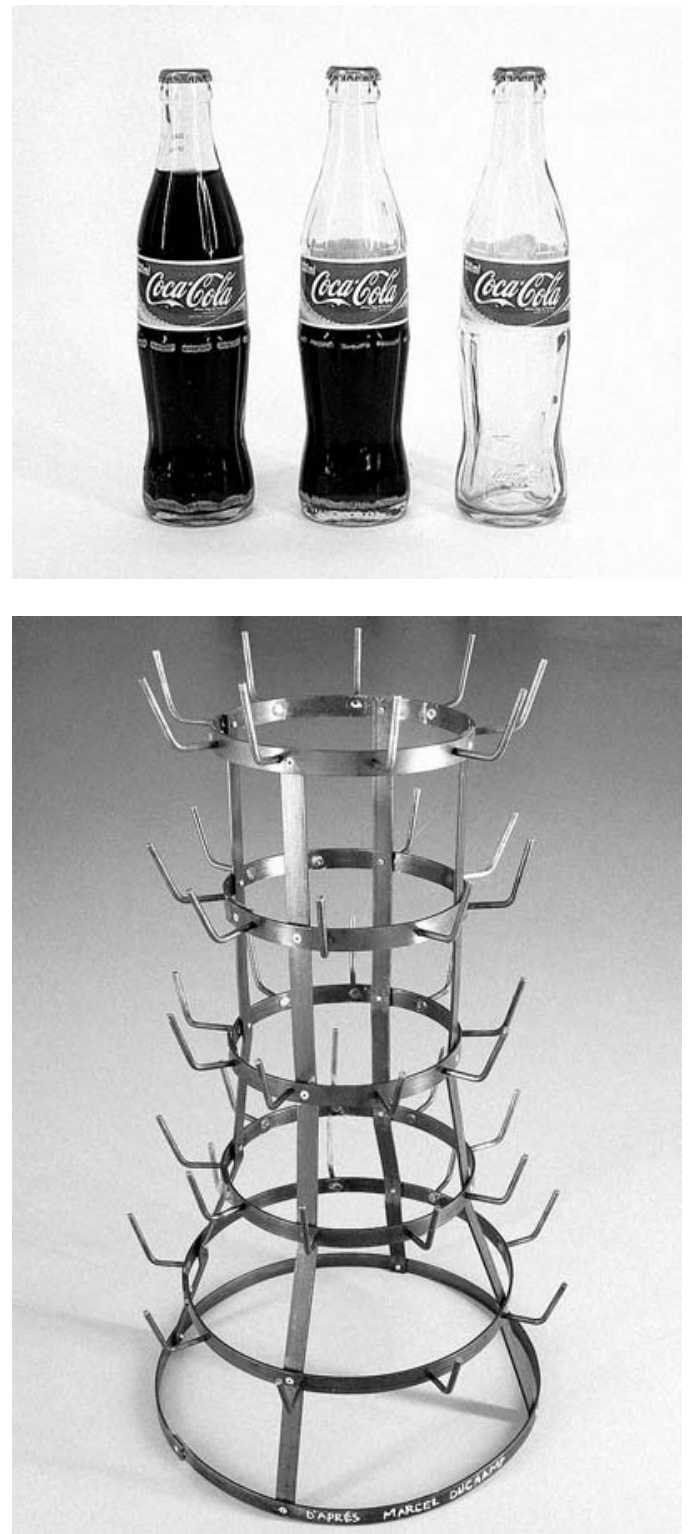

Segundo movimento: UbuWeb - As obras das vanguardas acessiveis via técnicas das vanguardas

Vídeos de acções, de performances e de conversas, uma rádio, filmes, gravações áudio, poemas, textos, manifestos, ensaios, livros e revistas inteiramente digitalizadas de Apollinaire, Cage, Cunningham, Augusto e Haroldo de Campos, Robert Filiou, Gomringer, Dan Graham, Dick 

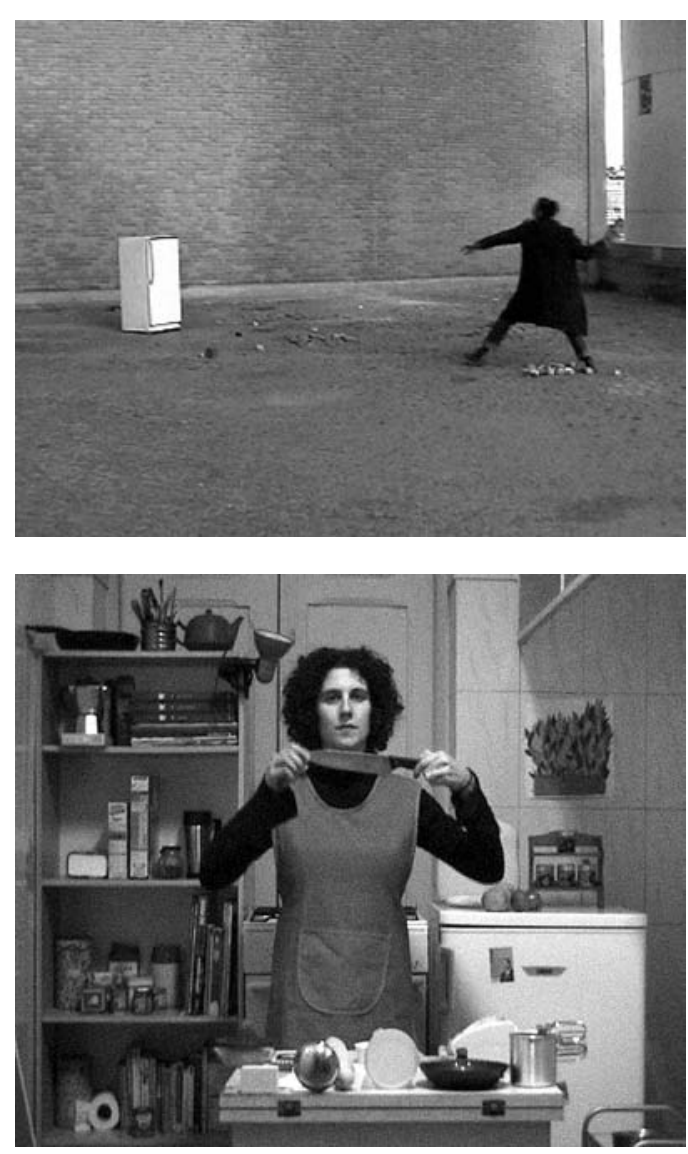

Higgins, Beckett, Kaprow, Yves Klein, John Lennon, Yoko Ono, Charlotte Moorman, Nam June Paik, Robert Rauschenberg, Kurt Schwitters, Lou Reed, Bob Wilson, Antonin Artaud, Emmett Williams, La Monte Young, Jerzy Grotowsky, Andy Warhol, etc., são alguns dos conteúdos e dos autores a que se tem acesso em UbuWeb um "depósito de poesia visual e concreta que, com o passar do tempo, foi abarcando todas as formas de manifestações de vanguarda".

Fundado por Kenneth Goldsmith ${ }^{2}$ em 1996, começou por consistir na digitalização e colocação online da colecção de livros e revistas de poesia visual do próprio Goldsmith. Esta, feita sem que para tal fosse pedida autorização aos respectivos autores, correspondia à vontade de recolocar gratuitamente em circulação obras que já não se encontravam disponiveis ou que eram de difícil acesso (e esta é uma das regras dos conteúdos de www.ubu.com não se colocam online trabalhos disponíveis no mercado) fazendo-o enquadrando-as num espaço claro, neutro, livre de publicidade e das pressões comerciais. Para Goldsmith, o facto de a internet possibilitar um livre acesso à informação e de em www.ubu.com o dinheiro não estar em jogo constitui um privilégio que permite que se possa como que "realizar o projecto utópico pan-internacionalista da poesia concreta". Constituindo-se como um

"interminável processo em construção" em que as pessoas diariamente enviam conteúdos, - hoje um dos mais consultados e pedagógicos depósitos das experiências de vanguarda, apoiado apenas por algumas universidades que gentilmente Ihe cedem a utilização dos servidores e a sua largura de banda - reclama-se como sendo agente de uma "economia da dádiva" - impossivel de existir se tivesse de funcionar de acordo com as regras das

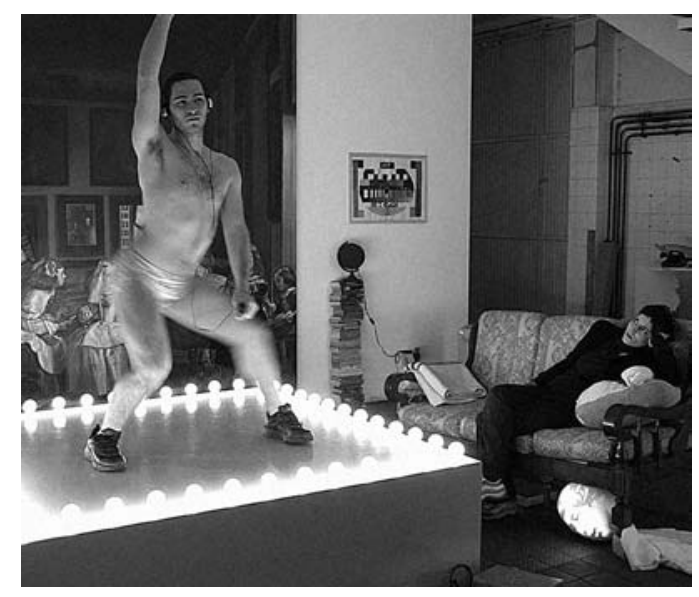

instituições - e avesso a fins comerciais. Estando organizado em cerca de 11 secções, uma rádio e um Hall of Shame - onde se assinalam os (raros, tendo em conta tudo o que está disponivel) materiais que tiveram de ser retirados por razões de autorização legal - em www.ubu.com encontrase de tudo, desde manifestos e poemas digitalizados a desconhecidas raridades ${ }^{3}$ das vanguardas - categoria que, de acordo com o fundador de UbuWeb, se encontra em colapso, o que permite uma criação - fácil e fértil - de novas relações entre alta e baixa cultura, público e privado e o carácter de "espaço na iminência de colapso" que UbuWeb prefigura para as categorias tradicionais.

Sobre o seu modo de funcionamento Goldsmith conta uma história: tendo digitalizado e colocado online um antigo livro de Robert Wilson, recebeu no dia seguinte uma carta da Robert Wilson Foundation em que davam conta do sucedido o que, diziam, muito Ihes agradava, embora pudesse ter sido feito com um simples pedido de autorização, ao que Goldsmith respondeu que se tivessem de pedir autorização de cada vez que colocam uma coisa online a UbuWeb não existia. Desde então a situação inverteu-se e, tendo respondido a isto declarando-se fãs do UbuWeb, a Robert Wilson Foundation (como muitos outros) agora propõe e envia conteúdos.

É de notar, porém (e Goldsmith também o enuncia), que as "formas de manifestação de vanguarda" presentes em UbuWeb se encontram todas naturalizadas e codificadas em formato digital, enquadradas num ambiente claro e acessivel ("a avant-garde torna-se como que sexy", diz), o que muitas vezes thes confere um papel que é justamente aquele contra o qual se posicionavam. Se a isto juntarmos o facto de se aceder a www.ubu.com utilizando justamente as (hoje naturalizadas e transformadas em ferramentas)
Projecto CASA, Pizz Buin 2007: St. Frigo, a partir do original de Jimmie Durham, 1997.

Projecto CASA, Pizz Buin 2007: Semiotics of the Kitchen, a partir do original de Martha Rosier, 1975. 0 original pode ver-se no UbuWeb, de onde o colectivo o "copiou".

Projecto CASA,

Pizz Buin 2007: Every Week There is Something Different, a partir do original de Félix Gonzales-Torres, 1991.

2 Kenneth Goldsmith é artista, critico, professor universitário, poeta e fundador do www.ubu.com. A sua entrevista em Everything... é porventura o documento onde melhor se encontra explicitada a filosofia open source, copyleft, de gift economy e de practice utopian politics do projecto.

3 www.ubu.com não tem todas as formas de manifestação das vanguardas. Muitas das suas obras mais conhecidas (e justamente por o serem) não estão disponiveis; muitas vezes encontram-se obras menos conhecidas dos mesmos autores, o que não é menos interessante. 

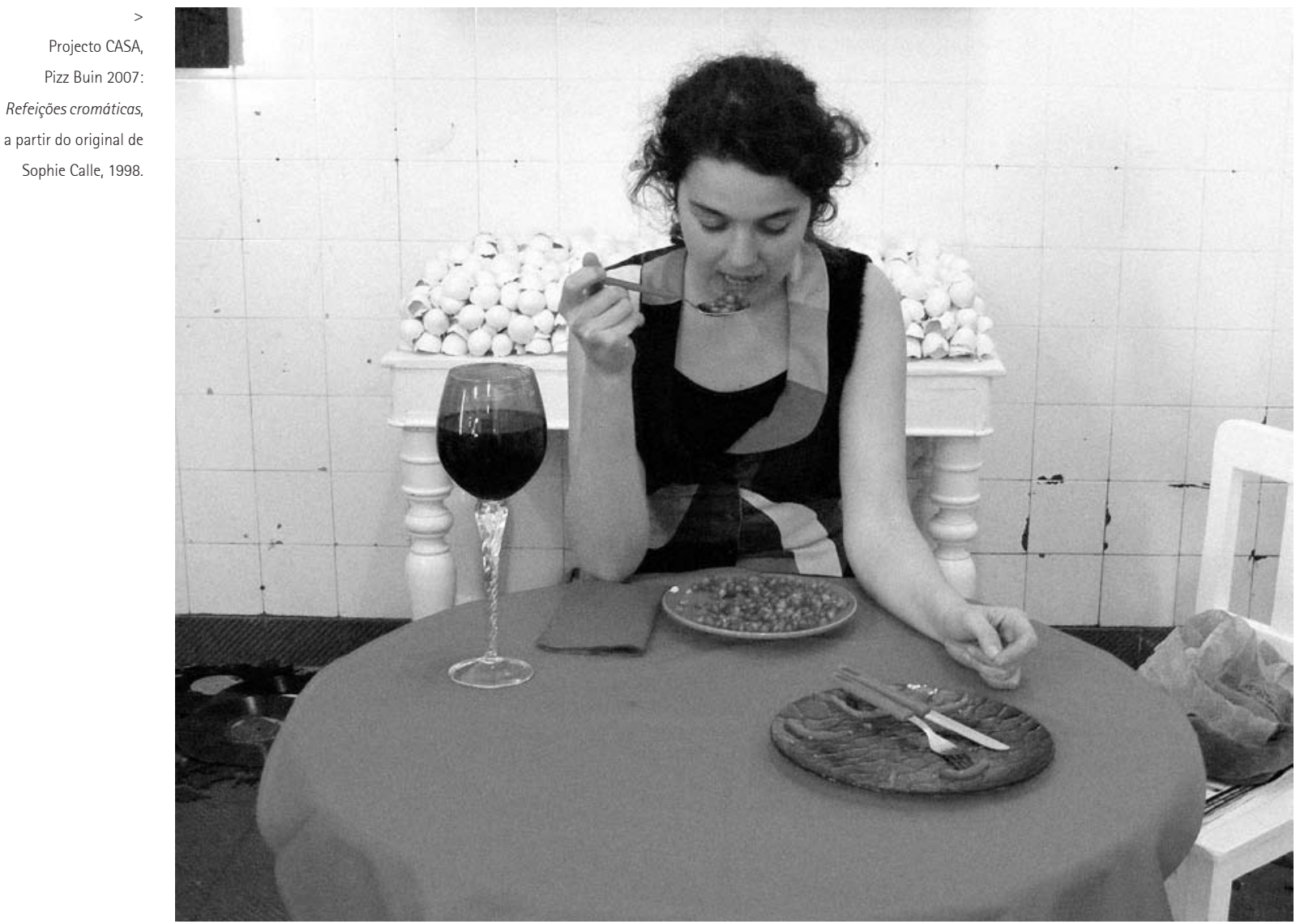

técnicas das vanguardas, é paradoxal a importância do computador ou como nova vanguarda (tese de Manovich) ou, pelo menos (como crê Goldsmith), como um lugar onde se pode pôr em prática um "sentido radical de distribuição" que, sem dúvida, não deixará de ter influência em futuros trabalhos de vanguarda.

Terceiro (e último) movimento: Uncreativity as a Creative Practice: o porquê das imagens do colectivo Pizz Buin

Uncreativity as a Creative Practice é o nome da "filosofia" que anima uma das disciplinas que Goldsmith lecciona na Universidade da Pensilvânia e cuja explicitação pode servir tanto para compreender melhor o espírito que anima a UbuWeb (e as possibilidades que um depósito feito nestes moldes oferece), como a escolha das imagens do colectivo Pizz Buin para ilustrar este texto. Trata-se de encorajar os alunos não a serem criativos - dado que este é um conceito que, nos dias que correm, se encontra em completa bancarrota - mas sim "não-criativos", aborrecidos até. Os estudantes são então encorajados a roubar, plagiar, partilhar, falsificar (caso Ihes apeteça) mas, sobretudo, a tornarem explicitas todas estas operações "que eles tão bem sabem fazer" e a considerarem-nas como estratégias absolutamente legitimas, a partir do que Goldsmith acredita poderem nascer coisas espantosas - como estas imagens do colectivo Pizz Buin, acrescentariamos.

0 colectivo Pizz Buin foi recentemente seleccionado para a mostra EDP Jovens Artistas com o projecto CASA que consistiu justamente em fazer cópias de obras de arte famosas e equipar com elas uma casa completa onde habitaram ao longo de um mês (e onde foram reproduzidas várias conhecidas performances) - abordando de um só golpe o mito da separação arte/vida, a questão da cópia, do original e da autoria, o carácter não utilitário da arte, a sua própria experiência enquanto pessoas completamente rodeadas de icones culturais e artísticos, e de estudantes de Artes Plásticas, habituadas a ter em casa obras uns dos outros.

É de salientar, na sua proposta, o carácter de remoção das obras de arte por elas copiadas do enquadramento "limpo" e domesticado que lugares como os museus, os livros de arte ou mesmo os depósitos como o UbuWeb Ihe oferecem, e a sua devolução à vida e às suas desarrumações. Mesmo que por pouco tempo.

GOLDSMITH, Kenneth, Everything You Ever Wanted To Know About UbuWeb, http://archinect.com/features/article.php?id=59857 $023 \mathrm{M}$.

LAZULY, Pierre (2003), "O mundo segundo o google", Le Monde Diplomatique, Março (disponivel online em http://diplo.uol.com.br/2003-10,a772). MACLUHAN, Marshal, www.marshallmcluhan.com.

MANOVICH, Lev (2000), "A vanguarda como software: Da 'nova visão' aos novos media", trad. Susana Nascimento, Revista de Comunicações e Linguagens n. ${ }^{\circ}$ 28: Tendências da cultura contemporânea, org. José Bragança de Miranda e Eduardo Prado Coelho, Lisboa, Relógio d'Água, pp. 421-439.

-- (2001), The Language of New Media, MIT Press.

-- www.manovich.net.

TSCHICHOLD, Jan (1995), The New Typography: A Handbook for Modern Designers, Berkeley, Univ. of California Press.

\section{Referências bibliográficas}

